\title{
Identificação in loco de atividades facilitadoras no processo construtivo de alvenaria estrutural junto aos gerentes de obra
}

Identification of extra-planning activities in structural masonry construction process: case study and interview with managers

\author{
P.R.R. Santos*; D. de G. Santos* \\ Departamento de Engenharia Civil, Universidade Federal de Sergipe,49.100-000, São Cristóvão - SERGIPE, Brasil
}

*paulo_ricardo.rs@hotmail.com;deboragois@yahoo.com.br

(Recebido em 09 de junho de 2015; aceito em 29 de outubro de 2015)

\begin{abstract}
O presente trabalho estuda a problemática da identificação de falhas na produção de edificações em alvenaria estrutural na busca de ações (boas práticas) que agreguem valor ao produto construído, chamadas aqui de atividades facilitadoras. Essas atividades quando inseridas no sistema de produção impedem ou minimizam as interrupções no trabalho. Elas podem estar incorporadas no processo ou auxiliá-lo. O objetivo da pesquisa foi identificar atividades facilitadoras no processo construtivo de elevação de alvenaria estrutural e investigar seu reconhecimento pelos gerentes. Buscou-se fazer uma conexão entre a Construção Enxuta e a prática cotidiana no canteiro de obra estudado. A metodologia aplicada contemplou pesquisa bibliográfica e estudo caso. $\mathrm{O}$ estudo realizou objetivos com características descritivas e baseou-se em um modelo de integração de atividades. Foi escolhido um empreendimento para investigação e coleta de dados que em seguida foi observado in loco. Entrevistas não estruturadas com a equipe técnica da obra foram realizadas. Utilizou-se também outras ferramentas como: registros fotográficos; consulta a projetos e elaboração de fluxos físicos (fluxograma). Como resultado, foi possível distinguir atividades facilitadoras e falhas no canteiro de obra analisado. As principais boas práticas e falhas identificadas a partir da aplicação da metodologia estavam ligadas aos insumos, classificando o fluxo e a gestão de materiais como pontos estratégicos no canteiro de obra. O estudo contribui para a disseminação de ideias enxutas na construção civil, a partir da proposição de atividades que propiciam o aumento da racionalidade.
\end{abstract}

Palavras-chave: atividades facilitadoras, construção enxuta, modelo de Integração.

The present study examined the issues of fault identification in the production of buildings in masonry and searched actions (good practices) that add value to the built product, called hair of extra-planning activities. These activities when inserted into the production system prevent or minimize interruptions of work. They may be incorporated into the process or help you. The objective of the research was to identify extra-planning activities in the construction process of structural masonry elevation and investigate its recognition by managers. It was made a connection between the Lean Construction and the daily practice in the studied site. The methodology included literature review and case study. The study presented goals with descriptive characteristics and was based on an activity integration model. It was chosen a project to research and to data collection. Unstructured interviews with the technical team of the work were carried out. It also used other tools such as photographic records; consulting projects and development of physical flows (flow chart). As a result, it was possible to distinguish extra-planning activities and failures in the analyzed site. The main good practices and failures identified using the method were linked to inputs, classifying the flow and materials management as strategic points on the site. The study contributes to the spread of lean ideas in construction, from the proposition of activities that provide increased rationality.

Keywords:extra-planning activities, lean construction, integration model. 


\section{INTRODUÇÃO}

A construção civil tem muitos problemas, sobretudo, quanto ao uso de matérias primas. Sua cadeia de produção ainda apresenta grande quantidade de perdas. Muito disso se deve ao fato de que os agentes construtivos (operários, engenheiros, proprietários) ainda pensam e agem de forma artesanal [1].

Para que esse cenário mude, faz-se necessário investir em uma gestão de produção que atue como instrumento eficaz no aumento da racionalização e na melhoria da competitividade, com foco na importância do fluxo do trabalho. Uma forma de realizar este investimento é identificar boas práticas, ao combater às perdas no processo produtivo. Ohno (1997) [2] define o sistema produtivo como a completa eliminação de perdas. Nesse contexto, Ohno afirma ainda que o trabalho pode ser dividido no que adiciona valor e no que não adiciona valor ao produto. As perdas não adicionam valor ao produto do ponto de vista dos clientes internos e externos, logo deveriam ser eliminadas ou minimizadas.

Shingo (1996) [3] define as categorias de perdas como superprodução, transporte, processamento em si, movimentação, estoque, produtos defeituosos e espera. Observa-se que essas categorias de perdas relacionam-se com as atividades que não agregam valor, como transporte, estoque, inspeção e retrabalho. Além, da situação de espera, que ocorre quando não existe o desenvolvimento de uma atividade.

Entende-se que o retrabalho está ligado ao tempo improdutivo não apenas por ter que refazer o produto, mas, também, pelo tempo de espera para a identificação do erro, correção em projeto, interfaces com outros processos e, por fim, a reconstrução [4, 5]. Poder-se-ia dizer [6] que as esperas podem ser chamadas de folgas, ou seja, tempos onde os operários não estão realizando suas tarefas por estarem diante de operações irregulares, não previstas, que ocorrem de forma inesperada na produção.

Esse princípio de perdas foi criado por Ohno como um desafio proposto por Kiichiro Toyoda em 1945, a partir de estudos do modo de produção dos Estados Unidos. É um retorno às ideias de Taylor e Gilbreth's sobre tempos e movimentos [7].

$\mathrm{Na}$ construção civil, quando foi dito que os processos são formados por atividades de conversão e de fluxo, Koskela (2000) [8] preocupou-se com os dados de entrada para a realização de determinado processo, sendo estes denominados de sete fluxos, que devem se unir para o cumprimento de uma tarefa. Os sete fluxos são: projetos (informações), materiais/componentes, mão de obra, equipamentos, espaço, tarefas pré-requisito e condições externas.

É frequente nas atividades da construção civil ser observadas perdas na produção. Essas perdas resultam, muitas vezes, em retrabalhos e improvisações no canteiro de obras. Este tipo de perda relaciona-se com a categoria de perda making-do [9]. Esta categoria de perda foi definida a partir dos estudos de Ronen (1992) sobre o Kit completo [10]. Para o autor, making-do é a situação na qual a tarefa começa antes que todos os recursos necessários ao pacote de trabalho estejam disponíveis ou que seja dado segmento mesmo que esteja faltando algum item. $\mathrm{O}$ resultado pode ser perdas na qualidade do produto ou mesmo interrupções no processo que levarão a esta e a outras perdas.

Atualmente, verifica-se que os sete fluxos, definidos em Koskela (2000) [8], apresentam-se como as condições necessárias para se evitar o making-do, uma vez que são as entradas (inputs) necessárias para começar e continuar uma tarefa.

O making-do foi inspirado na síndrome de eficiência. Conforme Leshno e Ronen (2001) [11], a síndrome de eficiência é o desejo de utilizar tantos recursos quanto possível. É comum que os supervisores queiram que o pessoal esteja ocupado o tempo todo, apenas para que não fiquem ou não aparentem estar ociosos. Isto resulta em mais trabalho em processo, menos rendimento e mais despesas operacionais.

Podem-se associar as perdas da qualidade com a ausência de aplicação de boas práticas e as interrupções no trabalho com a ausência da aplicação de atividades que facilitem o trabalho, sendo a ausência destas últimas mais críticas do que das primeiras. Assim, observa-se que, ao analisar situações que levam à interrupção no trabalho, Santos (2004) [12] sugere a aplicação de ações ligadas às categorias de atividades para eliminar ou minimizar esse efeito. Esta seria uma 
forma de combater o making-do. O que a autora denomina de categoria de atividades facilitadoras.

Verifica-se que situações semelhantes ocorreram com diversos autores ao buscarem introduzir atividades que evitem o making-do, seja estudando o retrabalho, a improvisação ou o trabalho em processo, a exemplo de Sommer (2010) [13], Formoso et al. (2011) [14], Fireman et al.(2013) [15], Fireman (2012) [16] e Leão (2014) [17].

Conforme já mencionado, é sabido que boas práticas são ações de melhorias adotadas em determinado setor para auferir à atividade produtiva mais eficácia e eficiência, por meio da realização de tarefas [18].

- Quando as atividades de boas práticas contribuem para evitar interrupções no processo, são chamadas de atividades facilitadoras (AF's).

As atividades facilitadoras são definidas como ações que quando inseridas no sistema de produção impedem ou minimizam as paradas, ou seja, as descontinuidades ao longo do processo produtivo. "Elas podem estar incorporadas no processo ou auxiliá-lo. Apresentam-se como atividades de produção, de apoio à produção ou ainda como informações" (SANTOS, 2004, p. 91) [12].

A disseminação de boas práticas pode ser realizada por meio de treinamento com os gestores e com acadêmicos. Mesquita (2014) [19] obteve este retorno ao aplicar jogo didático simulativo.

Quando as boas práticas contribuem para evitar interrupções no processo são chamadas de atividades facilitadoras [12]. Elas se relacionam com o conceito de melhoria contínua [1], favorecendo um fluxo contínuo de produção e envolvendo a incorporação de informações ao processo que evitarão mais tarde condições subótimas de trabalho [8]. Elas também minimizam eventuais problemas de entradas que viriam a desfigurar o kit completo [10, 11]. Por outro lado, ponto frágil se contrapõe à atividade facilitadora e às boas práticas, ameaçando o fluxo de produção [19].

O objetivo do trabalho reside na identificação de atividades facilitadoras do processo construtivo de elevação de alvenaria estrutural no canteiro de obras e qual a percepção dessas pelos gerentes de obra.

\section{MATERIAL E MÉTODOS}

A pesquisa ocorreu na forma de um estudo de caso, envolvendo acompanhamento das atividades desenvolvidas em canteiro de obras. Todo estudo foi embasado em um modelo chamado de integração [12], que trata de um método de análise processual que utiliza instrumentos gerenciais da Engenharia de Produção, transpostos exclusivamente para a construção civil, com o intuito de identificar os problemas de gestão da produção. Santos (2004) [12] propôs este modelo para identificar atividades facilitadoras, mas o mesmo pode ser utilizado também para identificar boas práticas e pontos frágeis e agrupá-los em categorias. As categorias propostas são [11] (Quadro 1): acesso, preparação do trabalho, projeto, sequenciamento, conferência do trabalho, conflito espacial, proteção dos processos, proteção dos operários e programação de obras. 
Quadro 1: Categoria de atividades facilitadoras

\begin{tabular}{|c|c|}
\hline Categorias & Descrição \\
\hline (1) Acesso & $\begin{array}{l}\text { Relaciona-se com o acesso de recursos humanos e materiais aos } \\
\text { locais de trabalho. }\end{array}$ \\
\hline (2) Projeto & $\begin{array}{l}\text { São as características do projeto que possibilitam a sua } \\
\text { construtibilidade. }\end{array}$ \\
\hline $\begin{array}{l}\text { (3) Preparação do } \\
\text { trabalho }\end{array}$ & $\begin{array}{l}\text { É a disponibilização no posto de trabalho dos recursos de produção, } \\
\text { necessários ao início dos processos (entradas). }\end{array}$ \\
\hline $\begin{array}{l}\text { (4) Conferência do } \\
\text { trabalho }\end{array}$ & Está relacionada com as medidas de desempenho do processo. \\
\hline (5) Conflito espacial & $\begin{array}{l}\text { Relaciona-se com o confronto no espaço de elementos de construção } \\
\text { ou de categorias de mão de obra, para a realização de processos } \\
\text { diferentes, em um mesmo ambiente de trabalho. }\end{array}$ \\
\hline (6) Sequenciamento & Está relacionada com a ordem de produção de determinado processo. \\
\hline $\begin{array}{l}\text { (7) Proteção dos } \\
\text { operários }\end{array}$ & $\begin{array}{l}\text { Trata-se da preocupação com a disponibilização em canteiro de } \\
\text { equipamentos de proteção coletivos e individuais. }\end{array}$ \\
\hline $\begin{array}{l}\text { (8) Proteção dos } \\
\text { processos }\end{array}$ & $\begin{array}{l}\text { Observa-se a proteção do serviço de construção já concluído em } \\
\text { relação a outros a serem executados no mesmo ambiente }\end{array}$ \\
\hline $\begin{array}{l}\text { (9) Programação de } \\
\text { obra }\end{array}$ & $\begin{array}{l}\text { Esta categoria está relacionada com exigências de clientes fora de } \\
\text { hora, desrespeito a planos, definição de pacotes de trabalho, pedido } \\
\text { de material, relação com fornecedores e interferência do cliente. }\end{array}$ \\
\hline
\end{tabular}

Fonte: Adaptado de Santos (2004) [11] e Machado (2003) [20]

Adotou-se ainda consulta a documentos e a projetos, registros fotográficos, aplicação de checklist para a identificação das boas práticas e das atividades facilitadoras e checklist para verificação de atendimento de itens de norma técnica, elaboração de fluxos físicos (fluxograma), bem como entrevistas não estruturadas com os engenheiros residentes no empreendimento e estagiários.

O modelo de integração é dividido em três macro-etapas: Base, Identificação e Ação, precedidas da etapa preliminar, onde se procede a seleção da empresa e do empreendimento de análise. Este trabalho contemplou as duas primeiras etapas e a etapa preliminar.

$\mathrm{Na}$ etapa preliminar, o universo da pesquisa compreendeu os canteiros de Aracaju e da Grande Aracaju, Sergipe, de empreendimentos que adotam como sistema construtivo a alvenaria estrutural, que é o sistema adotado em grande parte das edificações financiadas pelo programa de governo Mica Casa Minha Vida, no estado de Sergipe. Em prol do estudo, optouse por uma empresa com boa qualificação no mercado. Em seguida, foi escolhido um empreendimento da mesma para a coleta de dados.

Por sua vez, na etapa Base, para construir a base de informações para o estudo, o canteiro foi observado diretamente e realizaram-se entrevistas não estruturadas com os engenheiros da obra e estagiários. Utilizou-se, para o auxílio de coleta e análise de dados, ferramentas como: registros fotográficos; consulta a projetos, procedimentos e cronogramas. Com os dados coletados foram elaborados fluxogramas para estudo dos fluxos físicos da elevação de alvenaria: fluxograma base com atividades facilitadoras, boas práticas e pontos frágeis críticos do serviço. Para a elaboração do fluxograma foram adotados os símbolos utilizados por Santos (2004) [12].

O fluxograma é um diagrama de fluxo de processo que permite a visualização de um dado processo, passo a passo [21], representando o fluxo de materiais e informações.

$\mathrm{Na}$ etapa Identificação, a partir da análise de documentos reunidos na etapa anterior, foi possível distinguir os pontos fortes, compreendendo as boas práticas e as atividades facilitadoras, dos pontos frágeis (as falhas no canteiro analisado), classificando-os conforme Quadro2. 
Quadro 2: Esquema de cores para classificação das atividades identificadas

\begin{tabular}{|c|c|}
\hline Cor & Descrição da atividade \\
\hline & Facilitadora formalizada e incorporada ao processo \\
\hline & Facilitadora incorporada, mas não formalizada \\
\hline & Não faz parte do processo, mas o interrompe \\
\hline & Incorporada ao processo, mas na prática não é realizada \\
\hline
\end{tabular}

Após a identificação das atividades (pontos fortes e frágeis), estas foram posicionadas, segundo seu momento de ocorrência, no fluxograma do procedimento executivo de elevação de alvenaria estrutural da obra estudada. Esse posicionamento se dava colocando as atividades dentro de setas e posicionando estas no fluxograma no ponto que deveria evitar uma interrupção do processo, que ocorreria caso a atividade não fosse utilizada.

\section{RESULTADOS E DISCUSSÃO}

O objeto de pesquisa foi denominado de Obra A e era formado por dois empreendimentos residenciais executados no sistema construtivo de alvenaria estrutural de blocos de concreto, contendo 31 torres. Por conta disso, a movimentação de insumos dentro do canteiro era intensa, principalmente de blocos (cerca de 10.000 unidades por semana) e de argamassa. Visando melhorias no suprimento da demanda, foi instalada uma fábrica de blocos no terreno vizinho, que também pertencia à construtora.

Nas visitas técnicas, as informações foram obtidas por intermédio de entrevistas com os engenheiros (de planejamento, de produção e supervisor) e estagiários, bem como com observações diretas do trabalho realizado. As perguntas eram do tipo não estruturadas, uma vez que eram feitas no decorrer do reconhecimento da obra e a veracidade das respostas podia ser constatada in loco, em tempo real. Além disso, pôde-se ter acesso aos documentos da obra, incluindo o Procedimento de Execução de Serviço (PES) de alvenaria, e aos projetos, incluindo o de paginação da alvenaria.

A partir da análise de documentos reunidos na etapa anterior, foi possível identificar pontos fortes (boas práticas e atividades facilitadoras) e pontos frágeis do processo de produção de alvenaria estrutural, Quadro 3. As atividades foram correlacionadas nas categorias de atividades facilitadoras. 
Quadro 3: Atividades facilitadoras, boas práticas e pontos frágeis identificados

\begin{tabular}{|c|c|c|c|}
\hline & Atividade & Categoria & Cor \\
\hline \multirow{5}{*}{ Atividades Facilitadoras } & Não execução de contrapiso (Laje zero) & (3) Preparação do trabalho & \\
\hline & Embutimento de tubulações elétricas na laje painel & (3) Preparação do trabalho & \\
\hline & $\begin{array}{c}\text { Embutimento de caixas de passagem elétrica na laje } \\
\text { treliçada }\end{array}$ & (3) Preparação do trabalho & \\
\hline & Transporte de blocos conforme requisição & (3) Preparação do trabalho & \\
\hline & Pré-montagem de kits hidráulicos & (3) Preparação do trabalho & \\
\hline \multirow{5}{*}{ Boas práticas } & Paletização de blocos & (3) Preparação do trabalho & \\
\hline & Adoção de caixinha elétrica que evita variabilidade & (3) Preparação do trabalho & \\
\hline & Projeto de modulação até a 3a fiada & (2) Projeto & \\
\hline & Instalação de fábrica de blocos próxima a obra & (1) Acesso & \\
\hline & Tratamento de vias para a circulação de máquinas & (1) Acesso & \\
\hline \multirow{3}{*}{ Pontos frágeis } & $\begin{array}{l}\text { Ausência de gabaritos de portas e janelas, e } \\
\text { escantilhões }\end{array}$ & (4) Conferência do trabalho & \\
\hline & Falta de difusão do PES de alvenaria & (3) Preparação do trabalho & \\
\hline & $\begin{array}{l}\text { Variabilidade de quanto a ferramenta de aplicação de } \\
\text { argamassa }\end{array}$ & (3) Preparação do trabalho & \\
\hline
\end{tabular}

No exemplo de atividade facilitadora de transporte de blocos, do local de armazenamento para as torres com requisição, verificou-se que foi especificado o tamanho, a quantidade, a resistência e o local onde os blocos seriam utilizados. Dessa maneira, eram evitadas perdas decorrentes de um grande estoque de material no local de trabalho (possíveis quebras, transportes secundários, etc.).

Quanto à variabilidade de aplicação da argamassa, observou-se que nenhuma das ferramentas citadas era a que estava descrita no procedimento operacional da empresa. Isso refletia na produção. Os pedreiros que utilizavam espátula chegavam a produzir três vezes mais que os pedreiros que utilizavam colher, inserindo variabilidade ao tempo de ciclo (lead time) de cada pavimento.

Os fluxogramas apresentados nas Figuras 1 e 2representam o processo de elevação de alvenaria com a inserção das atividades facilitadoras e pontos frágeis. Essas atividades, identificadas e listadas no Quadro 3, foram inseridas no fluxograma até o momento que podem evitar ou minimizar a interrupção.

Todas as atividades facilitadoras se adequaram à cor verde - por não serem formalizadas nos documentos operacionais da empresa - e à categoria preparação do trabalho. Os pontos frágeis se encaixaram na categoria conferência do trabalho e preparação do trabalho, sendo atribuída a eles a cor roxa, ou seja, deveriam fazer parte do processo, mas não fazem. 


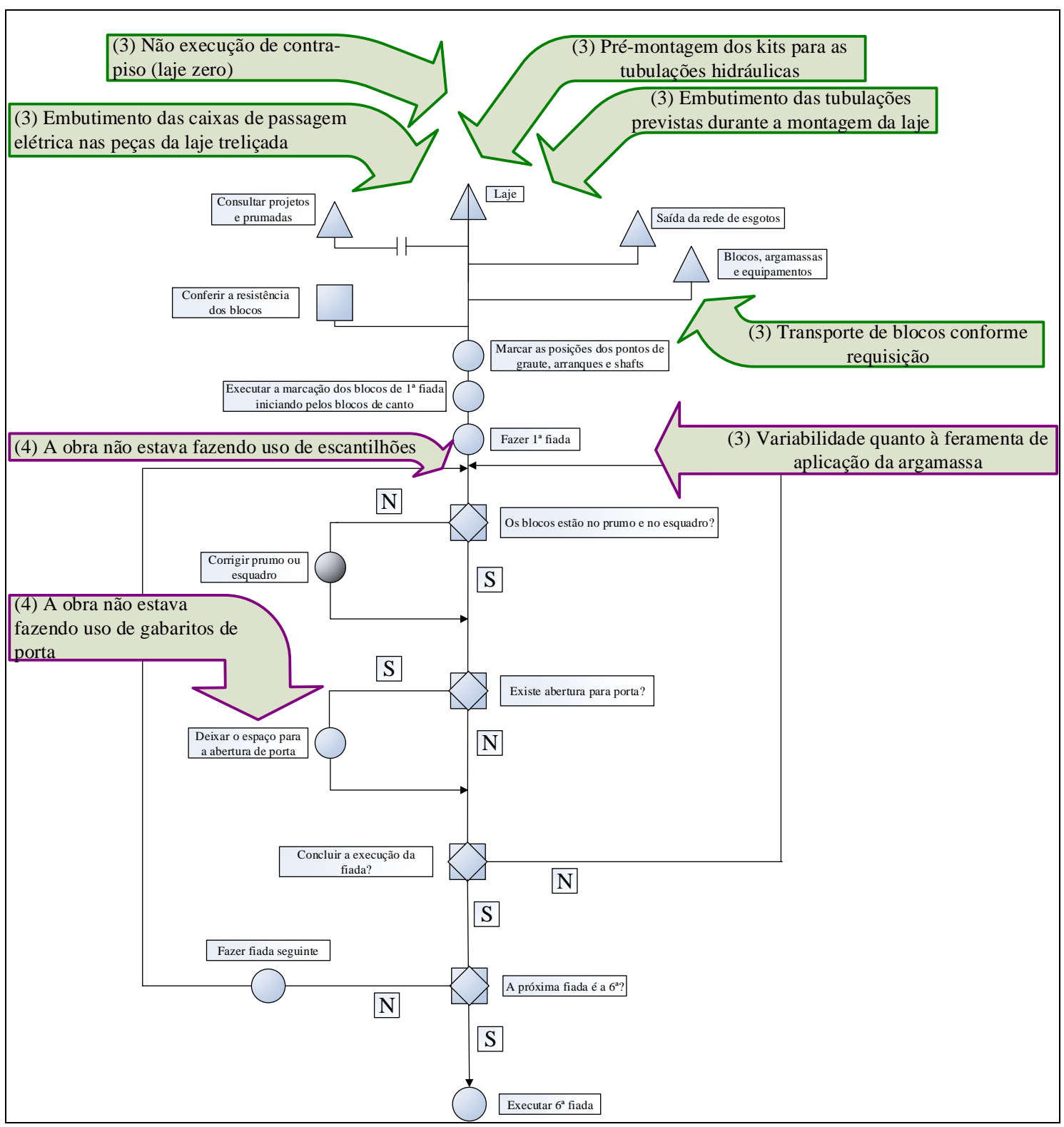

Figura 1: Fluxograma do processo de elevação de alvenaria com a inserção das atividades facilitadoras e pontos frágeis (parte A)

A laje do tipo painel, produzida no canteiro, permitia a não execução de contrapiso. Dessa forma, durante a concretagem da laje, havia a preocupação em deixá-la nivelada e devidamente regularizada. Assim, a primeira fiada do pavimento podia ser executada diretamente na laje com o auxílio da argamassa de assentamento. Essa atividade foi considerada facilitadora por remover uma etapa do processo, no caso, a execução do contrapiso. Outra atividade facilitadora identificada foi o embutimento das tubulações elétricas previstas, Figura 3. A junção de duas etapas do processo contribuiu para um melhor andamento da produção.

A fabricação da laje do tipo treliçada pré-moldada também foi contemplada com racionalização. As caixas de passagem da tubulação elétricas já eram embutidas durante a sua fabricação, Figura 4, (atividade facilitadora), que ocorria no próprio canteiro de obra.

Outra ideia de racionalização adotada foi a pré-montagem das tubulações hidráulicas utilizadas nas edificações. Para isso, buscou-se a padronização dos modelos hidráulicos usados para cada tipo de planta. Os kits eram transportados para os apartamentos conforme eram requeridos e já chegavam prontos para ser instalado nas paredes, o próprio pedreiro fazia a instalação, eliminando a dependência de outro funcionário para a colocação dos tubos. 


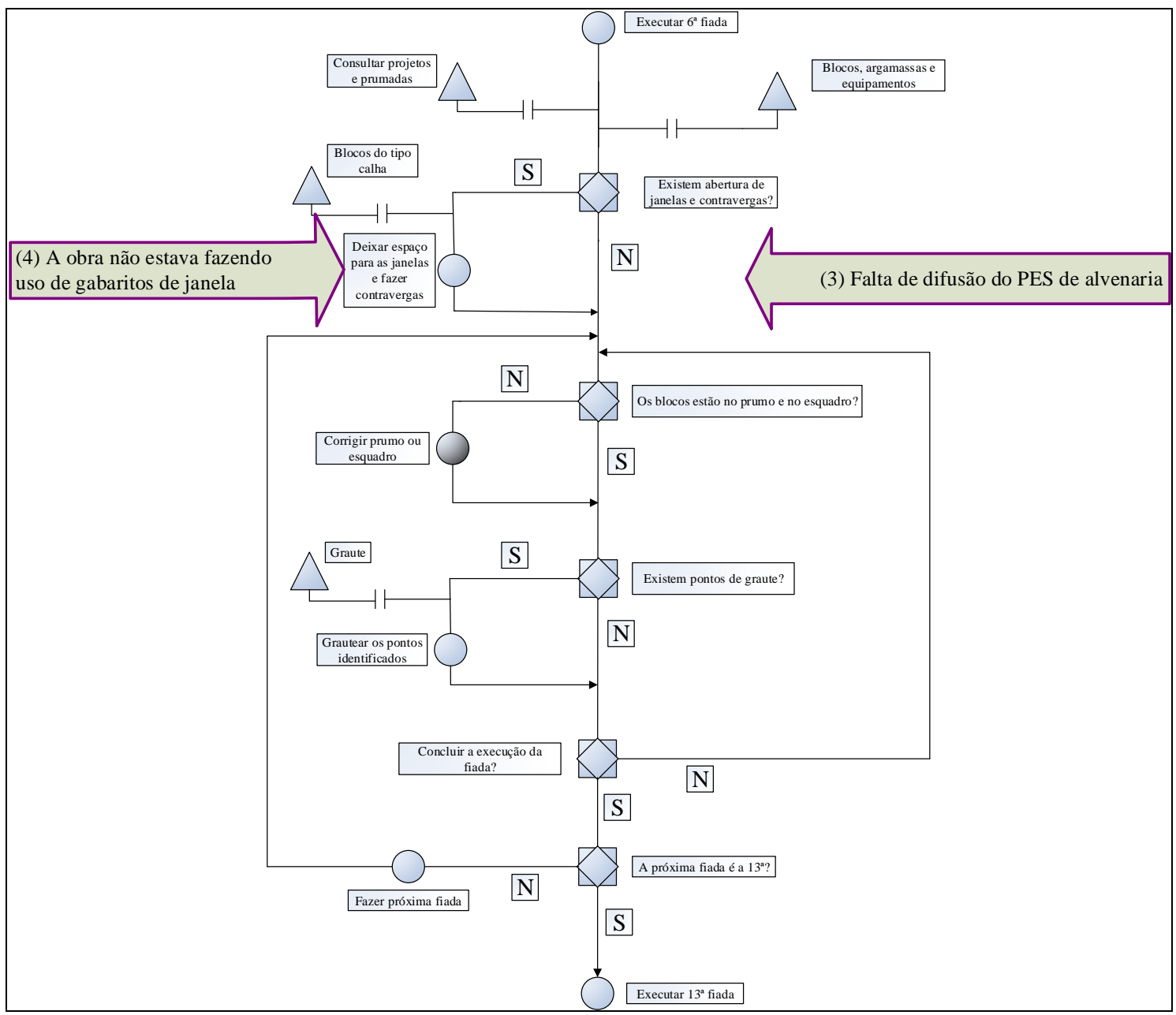

Figura 2: Fluxograma do processo de elevação de alvenaria com a inserção das atividades facilitadoras e pontos frágeis (parte B)

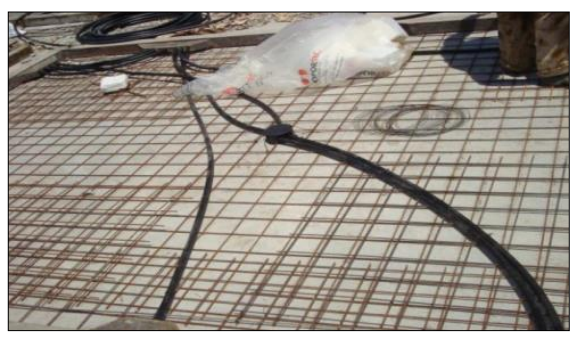

Figura 3: Tubulações embutidas na laje

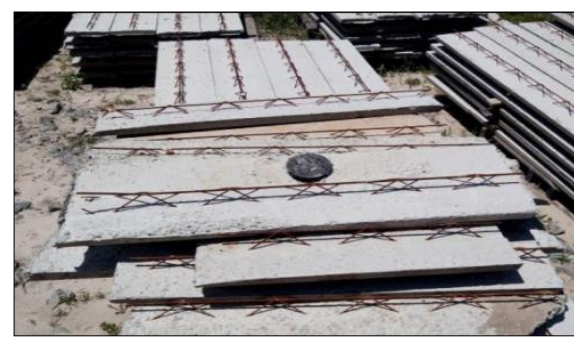

Figura 4: Peças da laje treliçada

Quanto aos pontos frágeis, a empresa não estava utilizando gabarito metálico de portas e janelas e nem escantilhões, pois estava aguardando a confecção dos mesmos. Os gabaritos de portas e janelas dão melhor precisão aos espaços destinados a esses elementos.

Os escantilhões auxiliam na correta elevação das fiadas, evitando que os blocos saiam do alinhamento nas extremidades das paredes. Esses três elementos deveriam ser usados e estarem incorporados ao processo, pois a tecnologia construtiva da alvenaria estrutural exige essas ferramentas. Além disso, retrabalhos podem ser necessários pela falta de precisão imposta pela ausência de tais ferramentas.

A aplicação da argamassa mostrou-se como o principal ponto de variabilidade da obra devido à variabilidade no tipo de ferramenta de aplicação (colher de pedreiro - na maior parte da obra-, bisnaga e uma espécie de espátula) (categoria de preparação do trabalho). O fator 
agravante dessa operação é que nenhuma das ferramentas citadas era a que estava descrita no procedimento operacional da empresa, ou seja, que deveria estar incorporada ao processo.

Quanto ao layout de canteiro, a escolha da instalação da fábrica de blocos (Figura 5) no terreno vizinho ganhou destaque como decisão acertada de implantação de canteiro, contribuindo para um melhor transporte na obra. O transporte foi um dos pontos fortes do canteiro, conforme exemplos de boas práticas da categoria de acesso. Os fatores que mais contribuíram para isso foram a boa variedade de máquinas, a boa distribuição das centrais de argamassa pelo canteiro, a localização da fábrica de blocos no terreno vizinho e a paletização de blocos, Figura 6.

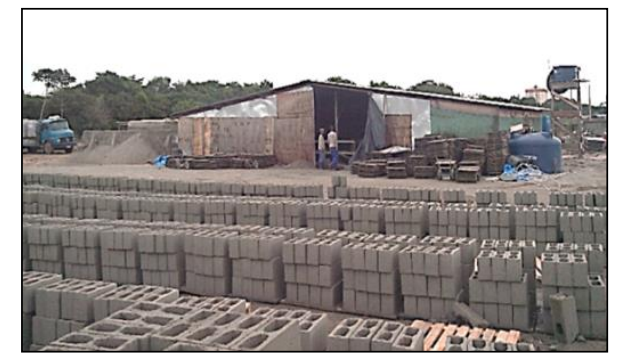

Figura 5: Fábrica de blocos

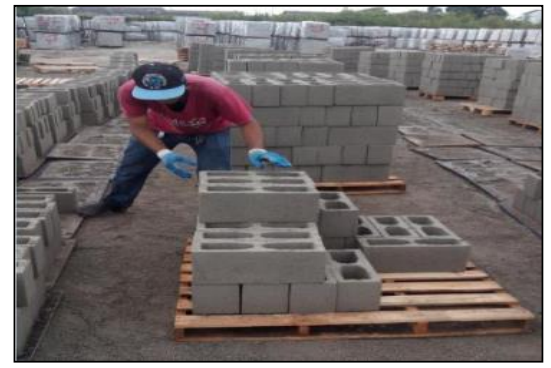

Figura 6: Paletização de blocos

Porém, no processo executivo encontraram-se muitas falhas, principalmente quanto ao cumprimento do PES de alvenaria.

\section{CONCLUSÃO}

O sistema construtivo encontrado na obra mostrou ser desenvolvido, a partir de um pensamento enxuto. $\mathrm{O}$ embutimento das instalações na produção das lajes, a não execução de contrapiso e a pré-montagem de kits hidráulicos comprovam isso. Isto pode ser observado nos exemplos de pontos fortes identificados, que foram em maior número do que os pontos frágeis.

Verificou-se que os pontos fortes identificados ocorreram na forma de boas práticas nas categorias de (3) preparação do trabalho, (1) acesso e (2) projeto. As atividades facilitadoras se encaixaram na (3) preparação do trabalho, revelando preocupação com a configuração do processo, por parte da equipe administrativa da obra, evitando, com isso, a perda por making-do.

Os pontos frágeis se apresentaram nas atividades de (4) conferência do trabalho e (3) preparação do trabalho. A aplicação de argamassa foi a atividade que mais apresentou variabilidade, principalmente na sua ferramenta de aplicação. A falta do uso de ferramentas necessárias ao processo (gabaritos e escantilhões) penalizou a produção com redução de precisão dimensional.

De modo geral, a aplicação do modelo de integração ocorreu com sucesso. As etapas foram executadas conforme modelo conceitual e assim foi possível distinguir as boas práticas, incluindo atividades facilitadoras, e falhas no canteiro de obra. As ferramentas utilizadas ajudaram a mapear bem o procedimento de elevação alvenaria estrutural.

Num balanço final, é possível concluir que o canteiro de obra em estudo foi contemplado com boas medidas de racionalização, revelando que os gerentes da obra estavam atentos às necessidades do processo. As principais boas práticas e falhas identificadas à luz do modelo estavam ligadas aos insumos encontrados na obra, dando ao fluxo e à gestão de materiais os papéis de protagonistas no canteiro de obra.

\section{AGRADECIMENTOS}

Ao CNPq pelo apoio recebido, Processo 144712/2014-8. 


\section{REFERÊNCIAS BIBLIOGRÁFICAS}

1. Koskela, L. Application of the new production philosophy to construction. Technical Report $\mathrm{n}^{\circ}$. 72 . Center for Integrated Facility Engineering. Stanford University, 1992. 87p.

2. Ohno, T. O sistema Toyota de produção: além da produção em larga escala. Porto Alegre: Bookman, 1997. $149 \mathrm{p}$.

3. Shingo, S. O sistema Toyota de produção do ponto de vista da engenharia de produção. $2^{a}$ edição. Porto Alegre: Bookman, 1996, 291p.

4. Love, P. E. D., Mandal, P., Li, H. Determining the causal structure of rework influences in construction. Construction Management and Economics, 1999; 17: 505-517.

5. Love, P. E. D., Mandal, P., Smith, J., Li H. Modelling the dynamics of design error induced rework in construction. Construction Management and Economics, 2000; 18: 567-574.

6. Antunes Junior, J. A V. O mecanismo da função de produção: a análise dos sistemas produtivos do ponto-de-vista de uma rede de processos e operações. Produção, Julho 1994; 4(1): 33-46.

7. Guinato, P. Sistema Toyota de Produção: mais do que simplesmente just-in-time. Caxias do Sul: Editora da Universidade de Caxias do Sul, 1996. 175p.

8. Koskela, L. An exploration towards a production theory and its application to construction. 2000. 298p. Doctor of Philosophy, Helsinki University of Technology, VTT Technical Research Centre of Finland, Espoo. 2000.

9. Koskela, L. Making-do: the eighth category of waste. In: Annual Conference of the International Group for Lean Construction, $12^{\text {th }}$, Elsinore, Denmark. 2004. Proceedings... Denmark, 2004. 10p.

10. RONEN, B. The complete kit concept. International Journal of Production Research, London, 1992; 30(10): 2457-2466.

11. Leshno, M.; Ronen, B. The complete kit concept - implementation in the health care system. Human Systems Management, 2001; 20: 313-318.

12. Santos, D. de G. Modelo de Gestão De Processos na Construção Civil para Identificação de Atividades Facilitadoras. 2004, 219p. Tese (Doutorado em Engenharia de Produção), Programa de Pós-Graduação em Engenharia de Produção, Universidade Federal de Santa Catarina. Florianópolis, 2004.

13. Sommer, L. Contribuições para um método de identificação de perdas por improvisação em canteiros de obras. 2010. 150p. Dissertação (Mestrado em Engenharia Civil). Programa de Pós-Graduação em Engenharia Civil, Universidade Federal do Rio Grande do Sul, Porto Alegre. 2010.

14. Formoso, C.T.; Sommer, L.; Koskela, L.; Isatto, E. L. An Exploratory Study on the Measurement and Analysis of Making-Do in Construction Sites. In: Annual Conference of the International Group for Lean Cconstruction, 19 ${ }^{\text {th }}$, 2011, Lima, Peru. Proceedings... Lima, 2011.

15. Fireman, M. C. T.; Formoso, C. T. Integrating Production and Quality Control: Monitoring MakingDo and Unfinished Work. In: Annual Conference of the International Group for Lean Construction, $21^{\text {th }}$, 2013, Fortaleza, Brazil. Proceedings... Fortaleza, 2013. p 515-525.

16. Fireman, M. C. T. Proposta de método de controle integrado da produção e qualidade, com ênfase na medição de perdas por making-do e retrabalho. 2012. Dissertação (Mestrado em Engenharia Civil). Programa de Pós-Graduação em Engenharia Civil, Universidade Federal do Rio Grande do Sul, Porto Alegre. 2012.

17. Leão, C. F. Proposta de modelo para controle integrado da produção e da qualidade utilizando tecnologia de informação. 2014. 179p. Dissertação (Mestrado em Engenharia) - Programa de PósGraduação em Engenharia Civil, Universidade Federal do Rio Grande do Sul, Porto Alegre. 2014.

18. Treville, S.; Antonakis, J. Could lean production job design beintrinsically motivating? Contextual, configurational, and levels-of-analysis issues. Journal of Operations Management, 2006; 24(2): 99123.

19. Mesquita, V. F. Desenvolvimento de jogo didático para tornar prático o uso das atividades que contribuem para a melhoria de processo: elevação da alvenaria estrutural. 2014. 174p. Dissertação (Mestrado em Engenharia Civil). Programa de Pós-Graduação em Engenharia Civil. Universidade Federal de Sergipe. São Cristóvão. 2014.

20. Machado, R. L. A sistematização de antecipações gerenciais no planejamento da produção de sistemas da construção civil. 2003. 264p. Tese (Doutorado em Engenharia de Produção), Programa de PósGraduação em Engenharia de Produção, Universidade Federal de Santa Catarina. Florianópolis. 2003.

21. Costa, F. Processo de produção de revestimento de fachada de argamassa: problemas e oportunidades de melhoria. 2005. Dissertação (Mestrado em Engenharia Civil). Escola de Engenharia, Programa de Pós-Graduação em Engenharia Civil,Universidade Federal do Rio Grande do Sul, Porto alegre. 2005. 